\title{
Insecticide Resistance in Anopheles Albitarsis S.S. From a Rice Production Field, With the First Record of Kdr Mutation in This Species
}

\section{Taiza Andrade Braga}

FIOCRUZ: Fundacao Oswaldo Cruz

\section{Aline Cordeiro Loureiro}

FIOCRUZ: Fundacao Oswaldo Cruz

José Bento Pereira Lima

FIOCRUZ: Fundacao Oswaldo Cruz

Ademir J Martins ( $\nabla$ ademirji@ioc.fiocruz.br)

Laboratório de Fisiologia e Controle de Artrópodes Vetores, Instituto Oswaldo Cruz, FIOCRUZ. Av Brasil 4365, Manguinhos, Rio de Janeiro - RJ. Brazil https://orcid.org/0000-0001-5739-1215

\section{Research}

Keywords: Neotropical Anopheles, pyrethroid, organophosphate, vector control, malaria vector, L1014F, $\mathrm{kdr}$

Posted Date: January 5th, 2021

DOI: https://doi.org/10.21203/rs.3.rs-139005/v1

License: (c) (i) This work is licensed under a Creative Commons Attribution 4.0 International License. Read Full License 


\section{Abstract}

Background: Although there is a vast literature concerning insecticide resistance (IR) in Plasmodium vectors from African and Asian continents, similar studies with Neotropical anophelines are scares. Herein we evaluated the IR profile of Anopheles albitarsis s.s. of a laboratory colony and a natural population collected around a rice plantation field. The laboratory colony is original from a collection performed in this same region more than two decades ago.

Methods: We collected An. albitarsis females while resting after blood feeding, around rice field plantations in Massaranduba, SC, Brazil. These females laid their eggs in the laboratory, and the larvae were raised in parallel with our lab colony. To be sure about the field samples' taxonomic status, we amplified and sequenced the mitochondrial $\mathrm{CO}$ /gene of a sampling of field captured mosquitoes. We performed a simplified knockdown test with larvae exposed to permethrin and deltamethrin and submitted adult females to a WHO like tube test with the pyrethroids permethrin, deltamethrin, and etofenprox, in addition to the organophosphate malathion. A segment of the voltage-gated sodium channel gene $\left(\mathrm{Na}_{\mathrm{V}}\right)$ was amplified and cloned. Based on the observed sequences, we developed a TaqMan genotyping assay for the variation L1014F and calculated the genotypic and allelic frequencies concerning this SNP in the field population.

Results: The COI analyses confirmed the taxonomic status of An. albitarsis s.s in laboratory and field samples. The field population was resistant to pyrethroids but not to malathion. We observed the substitutions L1019R, F1020S, and the classical $k d r$ L1014F in the $N a_{V}$ gene. This classical $k d r$ allele was present under low frequencies in the overall field population $(2 \%)$, although more frequent in pyrethroidresistant insects.

Conclusions: The An. albitarsis s.s. population from Massaranduba was resistant to pyrethroids, likely due to selection pressure exerted by agrochemical pesticides. We registered the classical $k d r$ mutation in a Brazilian Anopheles species for the first time. Further investigations are necessary to disclose additional resistance mechanisms.

\section{Introduction X}

Malaria is a neglected tropical disease that disproportionately affects the poorest and the most socially disadvantaged people, who generally have limited access to health care units and live in close contact with vector mosquitoes [1]. After more than a decade with constant advances in combat against malaria, reflecting in the decrease of incidence, this progress decreased, precluding the World Health Organization's (WHO) global goals toward malaria control and elimination until 2030 [2]. Vector control has been the key pillar to reduce the burden of malaria, with increased coverage of insecticide indoor residual spraying (IRS) and the distribution of long-lasting insecticide-treated nets (LLITN) [3]. However, the scale-up of insecticide-resistant Anopheline populations is a threat to vector control and, consequently, to malaria elimination plans [4]. Currently, at least 54 countries have reported the 
occurrence of Anopheles populations resistant to pyrethroid, which is the only recommended class of insecticides for LLITN and broadly deployed as in residual and spatial applications [5]. In Brazil, there are very few reports concerning insecticide resistance (IR) in Anopheles, regardless of the average of 203,182 yearly cases of malaria between 2010 and 2018 [5].

Pyrethroids and DDT target the voltage-gated sodium channel $\left(\mathrm{Na}_{\mathrm{V}}\right)$, which is a transmembrane neuron protein composed of four homologous domains (IIV), each with six hydrophobic segments (S1-S6) [6] [7]. The interaction between these chemicals and the channel prolongs its opening state and consequently causes a continuous propagation of the nerve impulse, causing repetitive muscular contractions, followed by death. This phenomenon is known as the knockdown effect [7] [8]. Non-synonymous substitutions in the $\mathrm{Na}_{V}$ gene are a crucial mechanism of resistance to pyrethroids and DDT and are therefore referred to as knockdown resistance mutations, or $k d r$ [9]. The amino acid substitution $L$ to $F$ in the $1014 \mathrm{Na}_{\mathrm{V}}$ codon (L1014F), placed in the IIS6 segment, has been associated with pyrethroid resistance in several insect species [10] [11] [12] [13], including at least 13 species of Anopheles from African, Asian and American regions [14]. In the Americas, the L1014F kdrmutation occurs in Anopheles albimanus populations from Mexico, Nicaragua, and Costa Rica [15]. The substitution L1014S is also common in An. sacharovi [16], An. gambiae s.I. (previously named as An. gambiae S form) [17], An. culicifacies [18], An. vagus, An. paraliae and An. peditaeniatus [19], An. stephensi [20], An. sinensis [21], An. arabiensis and An. coluzzi (previously named as An. gambiae M form) [22]. Additional alterations were observed, such as L1014C in An. sinensis [23] and An. albimanus in Latin América [15], L1014W in An. sinensis [21], V1010L in An. culicifacies [18] and N1013S in An. sinensis [21]. More than one kdrmutations can synergistically increase the levels of resistance to pyrethroid, as is the case of L1014F $+\mathrm{N} 1575 \mathrm{Y}$ in $A n$. gambiae [24] [25].

Anopheles darlingi is the principal malaria vector in the Brazilian Amazonian region, although other species are crucial to Plasmodium transmission in this country's malaria-endemic zones (Sinka et al., 2012; Carlos et al., 2019). This is the case of Anopheles albitarsis s.s, which belongs to the complex Albitarsis of cryptical spec[26]. Anopheles albitarsis s.s is distributed in the South of Brazil and North of Argentina and Paraguay, generally in plains, lowlands, and plateaus, and often under reduced occurrence in steep slopes and florets terrains [27] [28]. Although this species is preferentially zoophilous, females can feed on human blood in the absence of other large mammals [29] [30] [31]. Anopheles albitarsis s.s has been found around rice plantations and also collected in the domiciliary environment using human baits, suggesting that these flooded rural fields favor the maintenance of An. albitarsiss.s. under high densities, which is, therefore, an epidemiological concern in malaria-endemic areas [32].

Besides intervention targeting specific vector populations, the vast employment of agrochemicals in rural areas adjacent to malaria-endemic contributes to IR resistance selection in Anophelines [33] [34] [35] [36] [37]. Herein we evidenced that insecticides employed in rice plantations are selecting resistance in an An. albitarsis s.s. natural population, in a region free of malaria and hence without vector control interventions. The classical $k d r$ L1014F was observed, yet under low frequencies, and is the first report of such mutation in an Anopheles species from Brazil. 


\section{Methods}

\section{Laboratory and field strains.}

One strain of Anopheles albitarsis s.s. species is kept as an autonomously mating colony in the Laboratório de Fisiologia e Controle de Artrópodes Vetores (Laficave)/ IOC/Fiocruz, for more than two decades uninterruptedly. This colony was original from collections performed around a rice plantation field in Massaranduba, Santa Catarina State, Brazil (Horosko III et al., 1997). We performed new

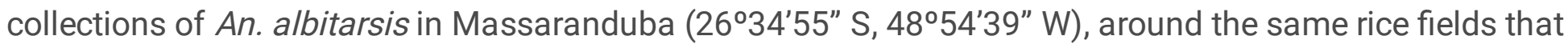
originated the laboratory colony over 20 years ago.

Local farmers informed us in Massaranduba that a variety of insecticides have been used in the rice fields at that time, such as Actara (thiamethoxam, Syngenta), EngeoTM Pleno (thiamethoxam + lambdacyhalothrin, Syngenta), Incrivel (acetamiprid + alfa-cypermethrin, Iharabras), Karate Zeon (lambdacyhalothrin, Syngenta), Mustang (zeta-cypermethrin, FMC) and Safety (etofenprox, Iharabras), in dosages varying from 160 to $200 \mathrm{~mL} / \mathrm{ha}$. Therefore, except for thiamethoxam, which is a neonicotinoid, all the other active ingredients were pyrethroids.

We performed the insect collections in corrals adjacent to flooded rice fields. We capture adult Anopheline females individually with a Castro aspirator [27] while resting on the walls after blood-feeding upon contained caws, $1-2 \mathrm{~h}$ after twilight. We gently transferred the insects to small carton cages maintained in a humid chamber while shipped to the laboratory. Two field collections were carried out: in February 2015 and February 2016. These collections were authorized by Instituto Chico Mendes de Conservação da Biodiversidade (ICMBio), SISBIO \# 48127-2. In the laboratory, we morphologically classified the insects as An. albitarsis, following the Anopheles key of Consoli e Lourenço-de Oliveira (1994) and were induced to lay eggs to obtain the F1 generation, as previously described [38]. It was necessary to maintain a new colony of An. albitarsis s.s. to generate a sufficient quantity of insects for bioassays with insecticides. Therefore, subsequent generations were obtained through artificial mating, similarly as performed by Klein et al. (1990)[39] and Lima et al. (2004)[40]. Hereafter we refer to the colonies as ALBI-lab (An. albitarsis s.s. lab colony) and ALBI-field (An. albitarsis s.s. colony recently collected from the field).

\section{Insectary conditions and mosquito rearing.}

Laboratory colonies of Anophelines have been maintained accordingly to Lima et al. (2004)[40], with few improvements. Briefly, larvae were reared in plastic trays with $0.1 \%$ sea salt solution in dechlorinated tap water. For larvae feeding, we daily pulverized groundfish food 'Marine Large Flakes' (Tetra, Melle) was over the water surface and replaced the salt-water solution whenever we noticed a high volume of food in the bottom of the tray. We transferred the pupae daily to cylindrical carton cages $(17 \times 17 \mathrm{~cm}$, diameter $x$ height), with a $10 \%$ sugar solution offered to adults ad libitum. Anesthetized guineapigs were the source of blood-feeding for females (license CEUA - LW-20/14). We introduced in the cages plastic cups internally covered with filter paper and filled with salt-water four days after the blood-feeding. We 
transferred the eggs to a tray until larvae hatching, which were then replaced to a new tray and reared as above. Larvae and adults were maintained in distinct environments with $28 \pm 1 \mathrm{C}$ and $26 \pm 1 \mathrm{C}$, respectively, in larvae and adult rooms. The relative humidity in adult rooms was maintained around $80 \%$ and a light/dark regimen of 12:12h. ALBI-field Colony was maintained similarly, except that we had to proceed with forced copulation and egg-laying induction, as aforementioned.

\section{Insecticide bioassays.}

\section{Larvicide.}

We performed the "Simplified knockdown bioassay" for Anopheline larvae, adapted from the Aedes protocol developed by Kawada et al. (2009)[41], as detailed by Silva et al. (2014)[42]. Briefly, we exposed 20 L4 larvae individually to a $20 \mathrm{~mL}$ pyrethroid deltamethrin (SIGMA-ALDRICH) solution in $50 \mathrm{~mL}$ plastic cups. Two concentrations were tested: 0.1 and $0.4 \mathrm{ppm}$ in 20 cups each, in addition to two cups containing $0.4 \mathrm{ppm}$ of the solvent acetone, as a negative control. The Larvae exposition lasted for 30 minutes, and the median knockdown time $\left(K d T_{50}\right)$, i.e., the time when half of the larvae (10) sank due to knockdown effect, were categorized in 1 (0-5 min), 2 (6-10 min), 3 (11-15 min), 4 (16-20 min), 5 (21$30 \mathrm{~min})$ and 6 (> $30 \mathrm{~min})$. The product of $K d \mathrm{~T}_{50}$ of 0.1 and $0.4 \mathrm{ppm}$ determined the susceptibility index (SI) of the strain, varying from 1 to 36 . The larger the $\mathrm{SI}$, the less susceptible the lineage was. In total, we have performed five independent assays in different days for ALBI-lab and ALBI-field (F5 generation of the 2015 field collection), totalizing 100 larvae of each strain tested per concentration. We obtained the average of the five assays as the final SI result.

\section{Adulticides.}

Bioassays with adult mosquitoes essentially followed World Health Organization-WHO tube test procedures [43] [44] with papers impregnated in our laboratory, instead. We performed a semi-quantitative time-response assay, where knockdown or mortality rates were monitored continuously until 120 minutes under exposure to the insecticide. The insecticides tested were the pyrethroids type I permethrin (0.75\%), type II deltamethrin (0.05\%), and the pseudo-pyrethroid etofenprox $(0.5 \%)$, in addition to the organophosphate malathion (5\%). These reagents were technical grade compounds (Pestanal, SigmaAldrich), dissolved in acetone, and diluted to their final concentration in silicone oil (Dow Corning). To impregnate the papers, we homogeneously distributed a total of $840 \mu \mathrm{L}$ of the insecticide solution in a $12 \times 14 \mathrm{~cm}$ filter paper (Whatman 1) and left it to air dry for two days. We used around 25 three to five days-old females per tube, in a total of three tubes/ insecticide/ strain. The negative control consisted of one tube containing paper impregnated only with the carrier silicone oil, in parallel to each test. We performed the whole assay twice, on different days for ALBI-lab e ALBI-field (F1 generation of the 2016 field collection). We submitted the recorded knockdown (pyrethroids) or mortality (organophosphate) data to Probit analysis, with the help of the software Statgraphics Centurion V. 16.103, in order to 
calculate the time of knockdown (KdT) or the lethal time (LT) to 50 and $90 \%$ of the lineages $\left(K d T_{50}\right.$ and $K d T_{90}, L_{50}$ and $L_{90}$, respectively). We determined the ALBI-field knockdown or lethal time resistant ratios (RR) of each insecticide relative to ALBI-lab by the quotient between their respective $K d T$ or $L T$ values.

\section{Molecular assays.}

\section{DNA extraction.}

We tittered each insect (adult females) in $250 \mu \mathrm{L}$ TNES lysis solution (250 mM Tris, $2 \mathrm{M} \mathrm{NaCl}, 100 \mathrm{mM}$ EDTA and $2.5 \%$ SDS) to obtain individual DNA [45], including a $56^{\circ} \mathrm{C}$ overnight incubation with $2 \mu \mathrm{l}$ Proteinase $\mathrm{K}(20 \mathrm{mg} / \mathrm{mL})$, and two alcoholic washes, first with $70 \%$ ethanol, followed by $100 \%$ isopropanol. We dissolved the final DNA pellet in $20 \mu \mathrm{L}$ TE buffer (1 mM EDTA, 10mM Tris-HCl) and checked the DNA concentration with the kit Qubit ${ }^{\circledR}$ dsDNA BR Assay (ThermoFisher Scientific) in a Qubit 3 Fluorometer (ThermoFisher Scientific). We deployed an aliquot of $20 \mathrm{ng}$ of each DNA sample to compose the ALBI-lab (200 samples) and ALBI-field (214 samples of the 2016 collection) DNA pools.

\section{Amplification and sequencing of a $\mathrm{COI}$ mitochondrial gene fragment.}

To confirm ALBI-field's taxonomic status, we amplified and sequenced the COI (Cytochrome c oxidase I) mitochondrial gene. We randomly selected the DNA of 11 ALBI-field and 10 ALBI-lab individual females for this analysis. We deployed the primers LC01490 (5'- GGTCAACAAATCATAAAGATATTGG-3') and HCO2198 (5'-TAAACTTCAGGGTGACCAAAAAATCA-3') [46] in a PCR amplification reaction as described elsewhere [47]. The purified amplicons were submitted to the Sanger sequencing method with the kit Big Dye 3.1 (Applied Biosystems) and followed to the DNA sequencing facility "Plataforma de Sequenciamento PDTIS/ Fiocruz". We checked the quality of electropherograms and aligned the sequences with homologous $\mathrm{CO}$ / sequences of the Albitarsis complex available in the GenBank (https://www.ncbi.nlm.nih.gov/genbank/): An. albitarsisH(DQ076222, DQ076223, DQ076224), An. deaneorum (DQ076226, DQ07 6227, DQ076229, DQ076230), An. albitarsis G (DQ076221, DQ076225) e An. oryzalimnetes (DQ076210, DQ076211, DQ076213, DQ0762105), with the software Geneious, v9.1.8 [48]. A Neighbor-joining ( $\mathrm{NJ}$ ) non-rooted tree was constructed, utilizing the Kimura-two-parameters model (K2P), with 1,000 permutations for Bootstrap, with the software Mega 7 [49].

\section{Amplification, cloning, and sequencing of the IIS6 segment of the voltage-gated sodium channel gene $(\mathrm{Na}))$.}

We used the primers 42F (5'- TCGTGTTTTATGCGGAGAATGG-3') and 422R

(5'CACGGACGCAATTTGACTTGT-3') designed for amplifying a fragment corresponding to An. darlingi 
IIS6 $\mathrm{Na}_{V}$ segment (Loureiro et al., submitted) for amplifying a fragment corresponding to the IIS6 $\mathrm{Na}_{V}$ segment. Amplification reactions made use of $1 \mu \mathrm{M}$ of each primer, $1 \mathrm{X}$ of the GoTaq Polymerase $2 \mathrm{x}$ (Promega ${ }^{\circledR}$ ), and $4 \mu \mathrm{L}$ of the DNA pool in a $40 \mu \mathrm{L}$ PCR reaction. Thermocycling conditions occurred as follow: $94^{\circ} \mathrm{C} / 3$ minutes, followed by 32 cycles of $94^{\circ} \mathrm{C} / 30$ seconds, $58^{\circ} \mathrm{C} / 30$ seconds, and $72^{\circ} \mathrm{C} / 1$ minute, for denaturation, primers annealing, and amplification, respectively, with an additional final step of $72^{\circ} \mathrm{C} / 3$ minutes. We submitted an aliquot of $4 \mu \mathrm{L}$ of the products to a $1 \%$ agarose gel electrophoresis to check the amplification of an expected $400 \mathrm{bp}$ amplicon. The remaining was purified with the kit Kit Agencourt AMPureXP (Beckman Coulter), according to the manufacture's instructions.

We ligated the purified amplicons $(4 \mu \mathrm{L})$ to the PJet plasmid with the CloneJET PCR Cloning Kit (Fermentas), submitted them to a transformation reaction with Escherichia coli DH5a competent cells in SOC medium (Invitrogen), and plated the transformed cells in an LB-agar solid medium with ampicillin $(100 \mathrm{mg} / \mathrm{mL})$ [45]. Around 96 colonies of each group were randomly selected and individually cultivated in $1 \mathrm{~mL}$ of CircleGrow (MP Biomedicals) liquid medium with ampicillin $0.075 \mathrm{mg} / \mathrm{mL}$, in a 96 deep well plate. We obtained the plasmidial purified DNA by an alkaline-lysis procedure (Sambrooke e Russel, 2001) and filtration in a $0.22 \mu \mathrm{m}$ filter microplate (Millipore). Purified plasmid DNAs $(1 \mu \mathrm{L}$, around $400 \mathrm{ng}$ ) were submitted to the Sanger sequence method with the kit Big Dye 3.1 (Applied Biosystems) and followed to the DNA sequencing facility "Plataforma de Sequenciamento PDTIS/ Fiocruz", as above. Sequences were evaluated and analyzed with Geneious, v9.1.8 (Kearse et al., 2012).

\section{Anopheles albitarsis kdr genotyping.}

Based on the obtained $\mathrm{Na}_{V}$ IIS6 An. albitarsis haplotypes, we developed a customized TaqMan SNP Assay (ThemoFischer) for the variations observed in the $1014 \mathrm{Na}_{\mathrm{V}}$ codon: TTA/ TTT $\left(\mathrm{Leu}^{+} / \mathrm{Phe}^{k d}\right)$. We used plasmidial DNAs of known sequences as positive controls $L / L$ and $F / F$. The heterozygote $L / F$ consisted of an equimolar mixture of both homozygotes. Once we have characterized insects with distinct genotypes, their DNA replaced the plasmidial DNA as positive controls.

Before the TaqMan SNP genotyping reaction, the IIS6 $\mathrm{Na}_{\mathrm{V}}$ segment was amplified, as described above, with individual DNA, in a reaction with half of that total volume. These products were 10X diluted and used in the TaqMan Genotyping SNP reactions, as follow: $1 \mu \mathrm{L}$ of 10X diluted IIS6 DNA, 1X TaqMan Genotyping Master Mix (Thermo Fischer), 1X CustomTaqMan SNP assay [primers: forward (5'GCATACCTTTCTTCTTAGCGACTGT-3') and reverse (5'-GCATGTTCGCAATGTTTGTATCAGT-3'), probes 1014 L (VIC- GAAACTTAGTCGTAAGTG) and $1014 \mathrm{~F}$ (FAM- GAAACTTTGTCGTAAGTG)], in a $10 \mu \mathrm{L}$ reaction. We performed these qPCR reactions in a QuantStudio ${ }^{\text {TM }} 6$ FlexSystem (Thermo Fischer), according to standard TaqMan genotyping procedures.

\section{Calculations.}


We obtained genotypic frequencies (L/L, $L / F$, and $F / F)$ by quoting the number of insects with the respective genotype and the total of evaluated samples. The formulas obtained the allelic frequencies:

$f(L)=2 n_{L / L}+n_{L / F} / 2 N$

$f(F)=2 n_{F / F}+n_{L / F} / 2 N$

where $\mathrm{n}$ is the number of insects with the respective genotype, and $\mathrm{N}$ is the total samples. We checked the Hardy-Weinberg Equilibrium by its classical equation [50].

\section{Results}

\section{Insecticide Bioassays}

\section{Larvae bioassays.}

A simplified knockdown assay obtained the Susceptibility Index (SI) to the pyrethroid deltamethrin. The total exposition time (30 minutes) to $0.1 \mathrm{ppm}$ deltamethrin was not sufficient to knockdown $50 \%\left(K d \mathrm{~T}_{50}\right)$ of the field Anopheles albitarsis s.s. (ALBl-field) larvae, whereas it was achieved between 15 and 20 minutes in the An. albitarsis s.s. lab colony (ALBI-lab) (Figure 1-a). In the higher dose, $4 \mathrm{ppm}$, the $K d \mathrm{~T}_{50}$ was between 10 and 15 minutes in ALBI-lab and 25 and 30 minutes in ALBI-field (Figure 1-b). The SI obtained for ALBI-lab and ALBI-field were, respectively, 12 and 30, suggesting that ALBI-field should present lower susceptibility to pyrethroid, compared to the lab colony (Figure 1-c).

The mean \% of mortality and respective standard deviations at every 5 minutes to the concentrations 0.1 and 0.4 ppm are showed in panels $\mathbf{a}$ and $\mathbf{b}$, respectively. In $\mathbf{c}$, the knockdown score in the left and resulting Susceptibility Index (SI) in the right. In all plots, An. albitarsis lab colony and field are represented in blue and red, respectively.

\section{Adult bioassays.}

We obtained the knockdown times (KdT) of ALBI-lab and ALBI-field adult females through WHO like test tubes, under two hours of exposition to the pyrethroids type I permethrin, type II deltamethrin, and pseudopyrethroid etofenprox. Likewise, we calculated the lethal times (LT) for the organophosphate malathion. The ALBI-lab females were 100\% knocked down in 60 minutes to all pyrethroids (Figure 2 and Table 1). On the other hand, only 50,64 , and $62 \%$ of ALBI-field females were knocked down to permethrin, deltamethrin, and etofenprox, respectively, in 60 minutes. The estimated times necessary to knockdown $90 \%$ of females were 4.0, 1.5, and $3.2 \mathrm{X}$ higher in ALBI-field than ALBI-lab, respectively, to permethrin, deltamethrin, and etofenprox (Table 1). In the case of malathion, both An. albitarsis s.s. groups did not present $100 \%$ of mortality before 60 minutes. However, both ALBI-lab and ALBI-field were $100 \%$ killed in 
less than 120 minutes. The profiles of this organophosphate were similar between An. albitarsis groups, with a slightly higher $\mathrm{LT}_{90}$ in the field population (Figure 2 and Table 1).

Time-response bioassay with the WHO recommended dose-diagnostic for the pyrethroids permethrin $(0.75 \%)$, deltamethrin $(0.05 \%)$ and etofenprox $(0.5 \%)$ and the organophosphate malathion $(5 \%)$. Lines are linear regression curves of knockdown (pyrethroids) or mortality (malathion) in Probit scale $x$ time minutes in log scale. The dotted line indicates $50 \%$ of knockdown or mortality.

\section{Molecular analyses}

\section{Molecular identification of a species in the An. albitarsis complex.}

We amplified and sequenced a fragment of $658 \mathrm{bp}$ of the $\mathrm{CO}$ / mitochondrial gene of ALBI-lab and ALBIfield samples. The nucleotide alignment and phylogenetic analysis with homologous sequences from different species of the An. albitarsis complex (An. deaneorum, An. oryzalimnetes, An. marajoara, An. albitarsis $G$ e An. albitasis $H$ ) showed that all ALBI-lab and ALBI-field sequences grouped in the monophyletic An. albitarsis s.s. clade (Figure 3), thus confirming their classification in this species. The ALBI-lab sequences were all identical, as expected to a homogeneous laboratory colony continuously maintained for more than 20 years.

Only Bootstrap values over $80 \%$ are exhibited. They were generated with 1,000 permutations. Samples of An. albitarsis from our colony (ALBI-lab) and the field (ALBI-field) are represented in light and dark blue, respectively. The other samples were retrieved from the GenBank, represented by their respective accession numbers. In green (An. albitarsis s.s.), black (An. oryzalimnetes), pink (An. deaneorum), grey (An. albitarsis $\mathrm{H})$, yellow (An. albitarsis $\mathrm{G})$, and purple (An. marajoara).

\section{Sequencing of the IIS6 $\mathrm{Na}_{\mathrm{V}}$ segment.}

We amplified, cloned, and sequenced the genomic region corresponding to the $\mathrm{Na}_{\mathrm{V}}$ IIS6 segment from DNA pools ALBI-lab (200 females) and ALBI-field (214 females). The fragment encompasses the exons 20 and 21, with an intron in between, and code for the amino acid sites 980 to 1080, following Musca domesticaNa ${ }_{V}$ gene numbering, as usually displayed. We obtained a total of 75 (ALBI-lab) and 68 (ALBIfield) sequences, resulting in five haplotypes for An. albitarsis s.s, with $379 \mathrm{bp}$. As expected, An. albitarsis s.s. $\mathrm{Na}_{V}$ sequences were highly conserved. ALBI-lab presented the haplotypes albi_1, albi_2, albi_3, and ALBI-field presented the haplotypes albi_1, albi_4, abi_5 (Figure 4). We found three non-synonymous substitutions: L1019R (albi_4), F1020S (albi_3), and the classical kdrmutation L1014F (albi_5) (Figure 4). Sequences are available at GenBank (accession numbers: MW315114- MW315118).

Amino acids and nucleotides are in blue and black, respectively. The numbering between brackets corresponds to the final nucleotide or amino acid at each block, according to the nucleotide alignment 
and following the Musca domesticaNa $V$ protein for the amino acids. Dots represent similar nucleotides, whereas nucleotide substitutions are in black or red when non-synonymous or synonymous. Nucleotides in upper case letters correspond to the $\mathrm{Na}_{V}$ exons 20 and 21, and the intron in between are in lower-case letters. The alignment region of primers employed for PCR amplification and cloning are underlined with a simple line and those for the L1014F genotyping SNP assays with a double line. The shaded region indicates where the L1014 and 1014F TaqMan probes hybridize.

\section{Genotyping of kdr L1014F in Anopheles albitarsis s.s.}

Once we observed the classical L1014F kdr mutation in clones from the ALBI-field pooled DNA, we genotyped the 214 samples that formed this pool, from which nine (4\%) presented the 1014F kdrallele, although all heterozygotes (1014 L/F). In this context, the $1014 \mathrm{~F} k d r$ allele was present in the frequency of $2 \%$ in the population (Table 2). The genotypic frequencies were under Hardy-Weinberg equilibrium $\left(X^{2}=0.046,1\right.$ d.f., $\left.P=0.7354\right)$. We additionally genotyped mosquitoes resulting from the bioassays with etofenprox and permethrin. Although with small sample size, it was noteworthy that the kdrallelic frequency was higher amongst resistant insects, i.e., alive after two hours of exposure to the insecticide (Table 2). Heterozygotes $1014 \mathrm{~L} / \mathrm{F}$ insects were found in both susceptible and resistant mosquitoes, although still in a higher frequency in the knockdown resistant insects. The only two homozygous $1014 \mathrm{~F} / \mathrm{F}$ females were resistant, one insect in each etofenprox, and permethrin assays (Table 2).

\section{Discussion}

At least 73 countries reported resistance to one insecticide class, among the 81 malaria-endemic countries that updated insecticide resistance monitoring data to WHO between 2010-2018. It is essential to highlight that 54 countries reported resistance to pyrethroids, the only class currently recommended for long-lasting insecticide-treated nets (OMS, 2019). Although malaria is a severe public health concern in Brazil, there are very few reports about insecticide resistance investigation. This fact highly contrasts with the extensive knowledge about insecticide resistance dynamics acquired with studies based on African anopheline populations. In this study, we determined the susceptibility profile of An. albitarsis s.s. from a laboratory colony and a field population to adulticides of different pyrethroids and one organophosphate.

We deployed a simplified knockdown bioassay adapted from Culex and Aedes larvae [41] to Anopheles [42] as a first panorama about the response to pyrethroids in larvae. Deltamethrin killed the An. albitarsis larvae from the lab colonies faster, scoring the larval susceptibility index (SI) 12 (the higher the index, the less susceptible is the population). Anopheline field populations from Amazon showed SI between 4 to 12 in Anopheles marajoara (a species of the An. albitarsis complex) and 4 to 15 in Anopheles darlingi populations. An IS of 15 was observed in An. darlingi from an urban locality in Manaus, Amazonia [42], where malaria and dengue vector control practices recurrently spray pyrethroids. Here, the field $A n$. albitarsis s.s. The population presented an SI of 30 , suggesting an altered profile compared to the lab colony and other neotropical anopheline species reported. 
We expected that our An. albitarsis s.s. colony was susceptible to insecticides. Even if the sampling that gave origin to the colonies had resistant alleles, they would probably lose resistance due to the fitness cost generally associated along these two decades inbred, under an environment free of insecticides in the laboratory [51] [52]). On the other hand, the field population was notably more tolerant than the laboratory line to the three pyrethroids, especially permethrin, but not to the organophosphate malathion. According to WHO criteria, the population is resistant if less than $90 \%$ survive 24 hours after the insecticide diagnostic dose exposition for 60 minutes. We did not check mortality 24 hours after since we extended the effect observations for 2 hours. In any case, all An. albitarsis s.s. females of the lab colony were $100 \%$ knocked down in 60 minutes of exposition to the three pyrethroids, while much less than $90 \%$ of field females were not moving at the bottom of the test tube at this time. Therefore An. albitarsis s.s. from Massaranduba is resistant to permethrin, deltamethrin, and etofenprox. This accentuated resistance profile to pyrethroids and not to malathion in the field population can be explained by the selection pressure constantly exerted in the rice plantations, where in addition to the neonicotinoid thiamethoxam, several pyrethroids (lambda-cyhalothrin, alfa-cypermethrin, zeta-cypermethrin, and etofenprox) have been employed, as informed by the local farmers. As An. albitarsis s.s. larvae bread in the flooded fields of rice plantations in Massaranduba, and not a single case of malaria has been registered in that region of the country for decades, it is much likely that pyrethroid agrochemicals are selecting resistance in this species.

The use of agrochemicals has continuously been associated with the selection of resistance in nontargeted insects, including species of sanitary importance. For instance, while the $K d T_{50}$ of the Anopheles gambiae Kisumu laboratory reference strain is 16 and 18 minutes to permethrin (0.75\%) and deltamethrin (0.05\%), respectively, populations collected around agricultural fields presented $K d T_{50}$ of 59,4 and 56,6 minutes in Kenya [53] and 152 and 38 minutes in Ghana [54], respectively to those pyrethroids. Here we observed a $K d \mathrm{~T}_{50}$ of 17.6 and 34.3 minutes in An. albitarsis s.s. colony, in contrast to 34.3 and 52.4 minutes in the population collected around rice farms, also to permethrin and deltamethrin, respectively. It is also interesting to observe that An. albitarsis s.s. from Massaranduba presented a higher resistance ratio to permethrin than deltamethrin, respectively pyrethroid types I and II.

Although the resistance to pyrethroids in An. albitarsis s.s. from Massaranduba has likely been selected during its larval phase in the flooded rice fields; the selected mechanism or mechanisms are expressed in both larval and adult phases, as observed in the bioassays. The two most studied physiological mechanisms selected for insecticide resistance are target site modification and increased metabolic detoxification power [55]. Here we found the occurrence of the classical kdr mutation L1014F in the An. albitarsis s.s. field population. At least 13 distinct Anopheles species presented substitutions in the 1014 $\mathrm{Na}_{\mathrm{V}}$ codon (Leu to Phe, Ser or Cys), especially the F1014F [14]. However, the only known neotropical anopheline species recorded with $k d r$ is the Anopheles albimanus, from Mexico (L1014F), Nicaragua (L1014C), and Costa Rica [15]. We developed a genotyping SNP assay specific for the L1014F kdr in An. albitarsis suitable for rapid and large-scale analysis. With this tool, we identified the kdrallele in $2 \%$ of $A n$. albitarsis s.s. parental field population, only in heterozygotes. Although this frequency is low, it can 
increase very rapidly in an environment under continuous selection pressure. This rapid increase happens because the $k d r$ phenotype is generally a recessive trait, in a way that only homozygote insects are resistant [56], as we observed when all $1014 \mathrm{~F} / \mathrm{F}$ insects were among those that survived to permethrin and etofenprox exposition. When the $k d r$ allele reaches a determined frequency referred to as the tipping point, it can increase exponentially in a few generations (OMS, 2012). As a practical example, in two An. gambiae populations from Benin, the $1014 \mathrm{~F} k d r$ allele increased from $20 \%$ and $6 \%$ to $74 \%$ and $90 \%$, respectively, in five years [33] [57]. Therefore, continuous molecular surveillance in natural populations is essential to identify alterations in the $k d r$ allele while its frequency is still low, making the management of insecticide possible before reaching critical values [58].

Curiously, we also observed the additional substitutions L1019R and F1020S, however, in our laboratory colony's DNA pool. To the top of our knowledge, these mutations are not described in other anophelines. However, the F1020S was observed in an Australian population of the moth Plutella [59] and two North American populations of the cockroach Blattella germânica [60]. In these species, the 1020S allele causes resistance to permethrin. However, L1019R and F1020S mutations are not $k d r$ in An. albitarsis, since our laboratory colony is not resistant to pyrethroid and has been maintained under an environment free of insecticide for more than two decades. Likely, these mutations are just retained polymorphisms, and they do not present any cost to the general insect fitness. On the other hand, we found the $k d r$ L1014F in An. albitarsis s.s. from Massaranduba under a low frequency.

Additional mutations in other $\mathrm{Na}_{\mathrm{V}}$ segments could be present, such as the I1527T substitution in the IIIS6 do $\mathrm{Na}_{\mathrm{V}}$ segment, detected in an An. gambiae population from Guinea resistant to pyrethroid [61], and the N1575Y, between domains III and IV, observed An. gambiaes.s. and An. coluzzi, from Congo, resistant to deltamethrin, permethrin, and DDT [62].

Otherwise, or summed with alterations in the target site, other mechanisms should have been selected in An. albitarsis s.s. from the field, as an increase in the detoxification power (metabolic resistance) and augment in the protection against insecticide penetration (cuticle hardening/ thickening mechanism) [63] [64]. The presence of additional $k d r$ mutations and evaluation of the expression profile of metabolic genes, especially P450 cyp genes and cuticle genes [65], need further investigation.

\section{Conclusion}

We characterized the insecticide susceptibility profile of An. albitarsis s.s. from a long-maintained laboratory colony, which is useful as a reference strain for insecticide susceptibility and Anopheline physiological studies. We came back 20 years after in the same region from where our colony was originated and observed that An. albitarsiss.s. from Massaranduba is now resistant to pyrethroids, very likely because larvae are breaded in flood rice fields where agrochemicals are used continuously. The classical $k d r$ mutation L1014F was for the first time described in a Brazilian Anopheles species. Further studies are needed to understand better the underlying mechanisms selected in this An. albitarsis s.s. population. 


\section{Declarations}

\section{Acknowledgments}

We thank the hospitable people from Massaranduba, especially the farm owners who kindly contained their cattle in the corrals at night, permitting us to make our collections. Additional thanks to the DNA sequencing facility at "Rede de Plataformas Tecnólogicas Fiocruz".

\section{Ethical statements}

We used anesthetized guinea pigs as the source of blood to feed the females to maintain the laboratory colonies, according to the approved license CEUA - LW-20/14, Instituto Oswaldo Cruz, FIOCRUZ.

\section{Authors' contributions}

TAB did the collections, reared the colonies, did biological and molecular assays. ACL participated in the collections and gave support in the molecular assays. JBPL leads the group and maintains the laboratory insect colonies. AJM designed the study, participated in the collections, reviewed the analyses, and prepared the manuscript's final version. All authors contributed to the writing process of this article and agreed to this final version.

\section{Data availability}

Genomic sequences generated in this study are available in the GeneBank. The corresponding author will provide additional data upon reasonable request.

\section{Funding}

Fundação Carlos Chagas de Filho de Amparo a Ciência do Rio de Janeiro (FAPERJ) and Instituto Nacional de Ciência e Tecnologia em Entomologia Molecular (INCT-EM).

\section{References}

1. WHO. Global technical strategy for malaria 2016-2030. World Heal Organ. 2015;1-35.

2. World Health Organization. World Malaria Report. Geneva; 2018.

3. Hemingway J. The role of vector control in stopping the transmission of malaria: Threats and opportunities. Philos. Trans. R. Soc. B Biol. Sci. Royal Society; 2014.

4. N'Guessan R, Corbel V, Akogbéto M, Rowland M. Reduced efficacy of insecticide-treated nets and indoor residual spraying for malaria control in pyrethroid resistance area, Benin. Emerg Infect Dis. 
2007;13:199-206.

5. World Health Organization. World Malaria Report 2019. Geneva. 2019.

6. Goldin AL. Evolution of voltage-gated Na+ channels. J Exp Biol. 2002;205:575-84.

7. Hemingway J, Hawkes NJ, McCarroll L, Ranson H. The molecular basis of insecticide resistance in mosquitoes. Insect Biochem Mol Biol. 2004;34:653-65.

8. Harrison CM. Inheritance of resistance to DDT in the housefly, Musca domestica L. Nature. 1951;167:855-6.

9. Hemingway J, Karunaratne S. Mosquito carboxylesterases: a review of the molecular biology and biochemistry of a major insecticide resistance mechanism. Med Vet Entomol. 1998;12:1-12.

10. Dong K. Rapid Communication A Single Amino Acid Change in the Para Sodium Channel Protein is Associated with Knockdown-Resistance (kdr) to Pyrethroid Insecticides in German Cockroach KE DONG*. Insect Biochem Molec Biol. 1997;27:93-100.

11. Smith TJ, Lee SH, Ingles PJ, Knipple DC, Soderlund DM. Rapid Communication The L1014F Point Mutation in the House Fly Vssc1 Sodium Channel Confers Knockdown Resistance to Pyrethroids. Insect Biochem Molec Biol. 1997;27:807-12.

12. Ponce G, Sanchez IP, García SM, Torrado JM, Lozano-Fuentes S, Lopez-Monroy B, et al. First report of L1014F kdr mutation in Culex quinquefasciatus in Mexico. Insect Sci. Blackwell Publishing Ltd; 2016;23:829-34.

13. Davila-Barboza J, Villanueva-Segura OK, Lopez-Monroy B, Ponce-Garcia G, Bobadilla-Utrera C, Montes-Rincon M, et al. Novel Kdr mutations (K964R and A943V) in pyrethroid-resistant populations of Triatoma mazzottii and Triatoma longipennis from Mexico and detoxifying enzymes. Insect Sci. Blackwell Publishing Ltd; 2019;26:809-20.

14. Silva APB, Santos JMM, Martins AJ. Mutations in the voltage-gated sodium channel gene of anophelines and their association with resistance to pyrethroids - A review. Parasites and Vectors. $2014 ; 7$.

15. Lol JC, Castellanos ME, Liebman KA, Lenhart A, Pennington PM, Padilla NR. Molecular evidence for historical presence of knockdown resistance in Anopheles albimanus, a key malaria vector in Latin America. Parasites and Vectors. 2013;6.

16. Lüleyap HÜ, Alptekin D, Kasap H, Kasap M. Detection of knockdown resistance mutations in Anopheles sacharovi (Diptera: Culicidae) and genetic distance with Anopheles gambiae (Diptera: Culicidae) using cDNA sequencing of the voltage-gated sodium channel gene. J Med Entomol. Entomological Society of America; 2002;39:870-4.

17. Santolamazza F, Calzetta M, Etang J, Barrese E, Dia I, Caccone A, et al. Distribution of knockdown resistance mutations in Anopheles gambiae molecular forms in west and west-central Africa. Malar J. 2008;7.

18. Singh OP, Dykes CL, Das MK, Pradhan S, Bhatt RM, Agrawal OP, et al. Presence of two alternative kdrlike mutations, L1014F and L1014S, and a novel mutation, V1010L, in the voltage gated $\mathrm{Na}$ + channel of Anopheles culicifacies from Orissa, India. Malar J. 2010;9. 
19. Verhaeghen K, Van Bortel W, Trung HD, Sochantha T, Keokenchanh K, Coosemans M. Knockdown resistance in Anopheles vagus, An. sinensis, An. paraliae and An. peditaeniatus populations of the Mekong region. Parasites and Vectors. 2010;3.

20. Singh OP, Dykes CL, Lather M, Agrawal OP, Adak T. Knockdown resistance (kdr)-like mutations in the voltage-gated sodium channel of a malaria vector Anopheles stephensi and PCR assays for their detection. Malar J. 2011;10.

21. Tan WL, Li CX, Wang ZM, Liu MD, Dong YD, Feng XY, et al. First detection of multiple knockdown resistance $(\mathrm{kdr})$-like mutations in voltage-gated sodium channel using three new genotyping methods in Anopheles sinensis from Guangxi Province, China. J Med Entomol. 2012;49:1012-20.

22. Badolo A, Traore A, Jones CM, Sanou A, Flood L, Guelbeogo WM, et al. Three years of insecticide resistance monitoring in Anopheles gambiae in Burkina Faso: Resistance on the rise? Malar J. 2012;11.

23. Kang S, Jung J, Lee S, Hwang H, Kim W. The polymorphism and the geographical distribution of the knockdown resistance (kdr) of Anopheles sinensis in the Republic of Korea. Malar J. 2012;11.

24. Jones CM, Liyanapathirana M, Agossa FR, Weetman D, Ranson H, Donnelly MJ, et al. Footprints of positive selection associated with a mutation (N1575Y) in the voltage-gated sodium channel of Anopheles gambiae. Proc Natl Acad Sci U S A. 2012;109:6614-9.

25. Wang L, Nomura Y, Du Y, Liu N, Zhorov BS, Dong K. A mutation in the intracellular loop III/IV of mosquito sodium channel synergizes the effect of mutations in helix IIS6 on pyrethroid resistance. Mol Pharmacol. 2015;87:421-9.

26. Ruiz-Lopez F, Wilkerson RC, Conn JE, McKeon SN, Levin DM, Quĩones ML, et al. DNA barcoding reveals both known and novel taxa in the Albitarsis Group (Anopheles: Nyssorhynchus) of Neotropical malaria vectors. Parasites and Vectors. 2012;5.

27. Consoli RAGB, Oliveira RL de. Principais mosquitos de importância sanitária no Brasil. Rio de Janeiro: FIOCRUZ; 1994.

28. Li C, Wilkerson RC. Identification of Anopheles(Nyssorhynchus)albitarsis complex species (Diptera: Culicidae) using rDNA internal transcribed spacer 2-based polymerase chain reaction primes. Mem Inst Oswaldo Cruz. 2005;100:495-500.

29. Forattini OP, Gomes A de C, Santos JLF, Galati EAB, Rabello EX, Natal D. Observações sobre atividade de mosquitos Culicidae em mata residual no Vale do Ribeira, S. Paulo, Brasil*. Rev Saúde Públ. 1981;15:557-86.

30. Lourenço-de-Oliveira R, Guimarães AE da G, Arlé M, Da Silva TF, Castro MG, Motta MA, et al. Anopheline species, some of their habits and relation to malaria in endemic areas of Rondônia state, Amazon region of Brazil. Mem Inst Oswaldo Cruz. 1989;84:501-14.

31. Érico Guimarães A, Pinto de Mello R, Macedo Lopes C, Alencar J, Gentile C. Prevalência de Anofelinos (Diptera: Culicidae) no Crepúsculo Vespertino em Áreas da Usina Hidrelétrica de Itaipu, no Município de Guaíra, Estado do Paraná, Brasil. Mem Inst Oswaldo Cruz, Rio Janeiro. 1997;92:74554. 
32. Forattini OP, Kakitani I, Massad E, Marucci D. Studies on mosquitoes (Diptera: Culicidae) and anthropic environment. 7-Behaviour of adults Nyssorhynchus anophelines with special reference to Anopheles albitarsis s.I. in South-Eastern Brazil*. Rev Saúde Pública. 1995;29:20-6.

33. Corbel V, N'Guessan R, Brengues C, Chandre F, Djogbenou L, Martin T, et al. Multiple insecticide resistance mechanisms in Anopheles gambiae and Culex quinquefasciatus from Benin, West Africa. Acta Trop. 2007;101:2017-216.

34. Ndjemaï HNM, Patchoké S, Atangana J, Etang J, Simard F, Bilong CFB, et al. The distribution of insecticide resistance in Anopheles gambiae s.l. populations from Cameroon: an update. Trans $\mathrm{R}$ Soc Trop Med Hyg. 2009;103:1127-38.

35. Nkya TE, Poupardin R, Laporte F, Akhouayri I, Mosha F, Magesa S, et al. Impact of agriculture on the selection of insecticide resistance in the malaria vector Anopheles gambiae: A multigenerational study in controlled conditions. Parasites and Vectors. 2014;7.

36. Africa W, Yadouleton A, Baba-moussa L, Klotoe J, Carine T, Tossou R, et al. Detection of multiple insecticide resistance mechanisms in Anopheles gambiae s.l. populations from the vegetable farming area of Houeyiho, Southern Benin, West Africa. Int J Mosq Res. 2018;5:21-7.

37. Philbert A, Lyantagaye SL, Nkwengulila G. Farmers' pesticide usage practices in the malaria endemic region of North-Western Tanzania: Implications to the control of malaria vectors. BMC Public Health. BMC Public Health; 2019;19:1-11.

38. Fontoura NG, Araki AS, Azevedo RVDM, Galardo AKR, Peixoto AA, Lima JBP. Hybrid sterility in crosses between two brazilian sibling species of the Anopheles albitarsis complex. Parasites and Vectors. 2014;7.

39. Klein TA, Lima JBP, Toda-Tang A. Colonization and maintenance of Anopheles deaneorum in Brazil. J Am Mosq Control Assoc. 1990;6:510-3.

40. Lima JBP, Valle D, Peixoto AA. Analysis of Reproductive Isolation Between Sibling Species Anopheles albitarsis sensu stricto and Anopheles deaneorum, Two Malaria Vectors Belonging to the Albitarsis Complex (Diptera: Culicidae). J Med Entomol. 2004;41:888-93.

41. Kawada H, Higa Y, Nguyen YT, Tran SH, Nguyen HT, Takagi M. Nationwide investigation of the pyrethroid susceptibility of mosquito larvae collected from used tires in Vietnam. PLoS Negl Trop Dis. 2009;3.

42. Silva APB, Alves WS, Martins Junior AJ, Tadei WP, Santos JMM. Adaptação de um bioensaio simplificado para avaliação do status de susceptibilidade em larvas de Anopheles darlingie Anopheles marajoara ao piretroide deltametrina. BioAssay. 2014;9.

43. World Health Organization. Test procedures for insecticide resistance monitoring in malaria vectors, bio-efficacy and persistence of insecticides on treated surfaces. Geneva; 1998 Sep.

44. WHO. Test procedures for insecticide resistance monitoring in malaria vector mosquitoes. World Heal. Organ. Tech. Rep. Ser. 2016.

45. Martins J, Solomon SE, Mikheyev AS, Mueller UG, Ortiz A, Bacci M. Nuclear mitochondrial-like sequences in ants: Evidence from Atta cephalotes (Formicidae: Attini). Insect Mol Biol. 2007;16:777- 
84.

46. Folmer Novo Nordisk O, Black M, Hoeh W, Lutz R, Vrijenhoek R. DNA primers for amplification of mitochondrial Cytochrome $\mathrm{C}$ oxidase subunit I from diverse metazoan invertebrates. Mol Mar Biol Biotechnol . 1994;3:294-9.

47. Fontoura NG, Araki AS, Van Der Maas Azevedo R, Galardo AKR, Peixoto AA, Lima JBP. Hybrid sterility in crosses between two Brazilian sibling species of the Anopheles albitarsis complex. Parasit Vectors. Springer Nature America, Inc; 2014;7:559.

48. Kearse M, Moir R, Wilson A, Stones-Havas S, Cheung M, Sturrock S, et al. Geneious Basic: An integrated and extendable desktop software platform for the organization and analysis of sequence data. Bioinformatics. 2012;28:1647-9.

49. Kumar S, Stecher G, Tamura K. MEGA7: Molecular Evolutionary Genetics Analysis Version 7.0 for Bigger Datasets. Mol Biol Evol. 2016;33:1870-4.

50. Shorrocks B. The genesis of diversity. Baltimore; 1979.

51. Kliot A, Ghanim M. Fitness costs associated with insecticide resistance. Pest Manag Sci. 2012;68:1431-7.

52. Belinato TA, Martins AJ. Insecticide Resistance and Fitness Cost. Insectic Resist Stanislav Trdan, IntechOpen. 2016. p. 243-61.

53. Kabula B, Tungu P, Matowo J, Kitau J, Mweya C, Emidi B, et al. Susceptibility status of malaria vectors to insecticides commonly used for malaria control in Tanzania. Trop Med Int Heal. 2012;17:742-50.

54. Adasi K, Hemingway J. Susceptibility to three pyrethroids and detection of knockdown resistance mutation in Ghanaian Anopheles gambiae sensu stricto . J Vector Ecol. 2008;33:255-62.

55. Liu N. Insecticide resistance in mosquitoes: Impact, mechanisms, and research directions. Annu. Rev. Entomol. Annual Reviews Inc.; 2015. p. 537-59.

56. Davies TGE, Field LM, Usherwood PNR, Williamson MS. DDT, pyrethrins, pyrethroids and insect sodium channels. IUBMB Life. 2007. p. 151-62.

57. Aïzoun N, Aïkpon R, Akogbéto M. Evidence of increasing L1014F kdr mutation frequency in Anopheles gambiae s.l. pyrethroid resistant following a nationwide distribution of LLINs by the Beninese National Malaria Control Programme. Asian Pac J Trop Biomed. 2014;4:239-43.

58. World Health Organization. Global plan for insecticide resistance management in malaria vectors. World Health Organization; 2012.

59. Endersby NM, Viduka K, Baxter SW, Saw J, Heckel DG, McKechnie SW. Widespread pyrethroid resistance in Australian diamondback moth, Plutella xylostella (L.), is related to multiple mutations in the para sodium channel gene. Bull Entomol Res. 2011;101:393-405.

60. Pridgeon JW, Appel AG, Moar WJ, Liu N. Variability of resistance mechanisms in pyrethroid resistant German cockroaches (Dictyoptera: Blattellidae). Pestic Biochem Physiol. 2002;73:149-56. 
61. Collins E, Vaselli NM, Sylla M, Beavogui AH, Orsborne J, Lawrence G, et al. The relationship between insecticide resistance, mosquito age and malaria prevalence in Anopheles gambiae s.l. from Guinea. Sci Rep. Nature Publishing Group; 2019;9.

62. Lynd A, Oruni A, Van'T Hof AE, Morgan JC, Naego LB, Pipini D, et al. Insecticide resistance in Anopheles gambiae from the northern Democratic Republic of Congo, with extreme knockdown resistance $(\mathrm{kdr})$ mutation frequencies revealed by a new diagnostic assay. Malar J. BioMed Central Ltd.; 2018;17.

63. Hemingway $\mathrm{J}$. The molecular basis of two contrasting metabolic mechanisms of insecticide resistance. Insect Biochem Mol Biol. 2000;30:1009-15.

64. Balabanidou V, Grigoraki L, Vontas J. Insect cuticle: a critical determinant of insecticide resistance. Curr. Opin. Insect Sci. Elsevier Inc.; 2018. p. 68-74.

65. Vontas J, Katsavou E, Mavridis K. Cytochrome P450-based metabolic insecticide resistance in Anopheles and Aedes mosquito vectors: Muddying the waters. Pestic. Biochem. Physiol. Academic Press Inc.; 2019.

\section{Tables}

Table 1. Time-response profile to pyrethroids and an organophosphate in An. albitarsis s.s. from the laboratory and field colonies.

\begin{tabular}{|lllll|}
\hline Insecticides & Knockdown or & \multicolumn{2}{ll}{ Time (IC95\%) in minutes } & ALBI-field/ \\
\hline & Lethal time & ALBI-lab & ALBI-field & ALBI-lab \\
\hline Permethrin 0.75\% & $K d T_{50}$ & $17.6(17.2-18.0)$ & $63.9(63.0-64.8)$ & 3.6 \\
\hline Deltamethrin 0.05\% & $K d T_{90}$ & $24.1(23.5-24.8)$ & $98.5(97.0-100.0)$ & 4.0 \\
\hline & $K d T_{90}$ & $34.3(33.4-35.3)$ & $52.4(51.4-53.3)$ & 1.5 \\
\hline Etofenprox 0.5\% & $K d T_{50}$ & $22.3(21.9-22.8)$ & $57.4(57.1-59.1)$ & 2.6 \\
\hline & $K d T_{90}$ & $31.1(30.5-31.9)$ & $98.8(97.2-100.5)$ & 3.2 \\
\hline Malathion 5\% & $\mathrm{LT}_{50}$ & $51.0(50.5-51.5)$ & $50.0(49.2-50.8)$ & 1.0 \\
\hline & $\mathrm{LT} 90$ & $62.1(61.3-63.0)$ & $75.2(74.0-76.4)$ & 1.2 \\
\hline
\end{tabular}

Table 2. L1014F genotyping of a natural Anopheles albitarsis s.s. population and of samples after bioassays with pyrethroids. 


\begin{tabular}{|lllllll|}
\hline Samples & \multicolumn{3}{c}{ Genotypic frequencies } & \multicolumn{2}{c|}{ Allelic frequencies } \\
& $\mathrm{N}$ & $\mathrm{L} / \mathrm{L}$ & $\mathrm{L} / \mathrm{F}$ & $\mathrm{F} / \mathrm{F}$ & $\mathrm{L}$ & $\mathrm{F}$ \\
\hline Field population & 214 & 0.957 & 0.042 & 0 & 0.98 & 0.02 \\
\hline Etofenprox - S & 20 & 0.850 & 0.150 & 0 & 0.93 & 0.08 \\
\hline Etofenprox - R & 8 & 0.625 & 0.250 & 0.125 & 0.75 & 0.25 \\
\hline Permethrin - S & 24 & 0.958 & 0.042 & 0 & 0.98 & 0.02 \\
\hline Permethrin - R & 4 & 0.500 & 0.250 & 0.250 & 0.63 & 0.38 \\
\hline
\end{tabular}

$\mathrm{S}$ and $\mathrm{R}$ refer to susceptible or resistant to the pyrethroid knockdown effect

Figures 
a

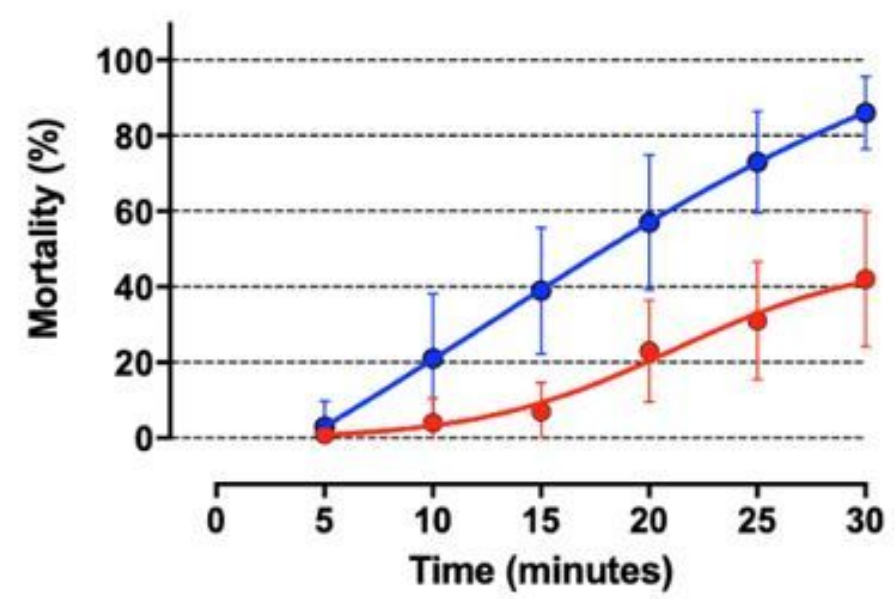

C

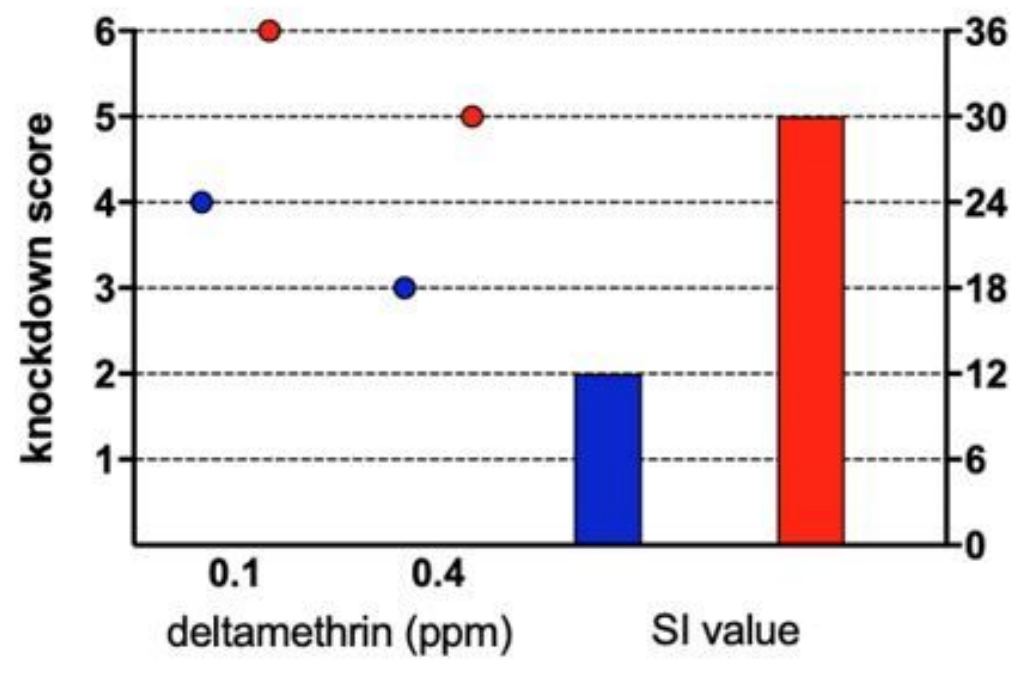

$0.4 \mathrm{ppm}$

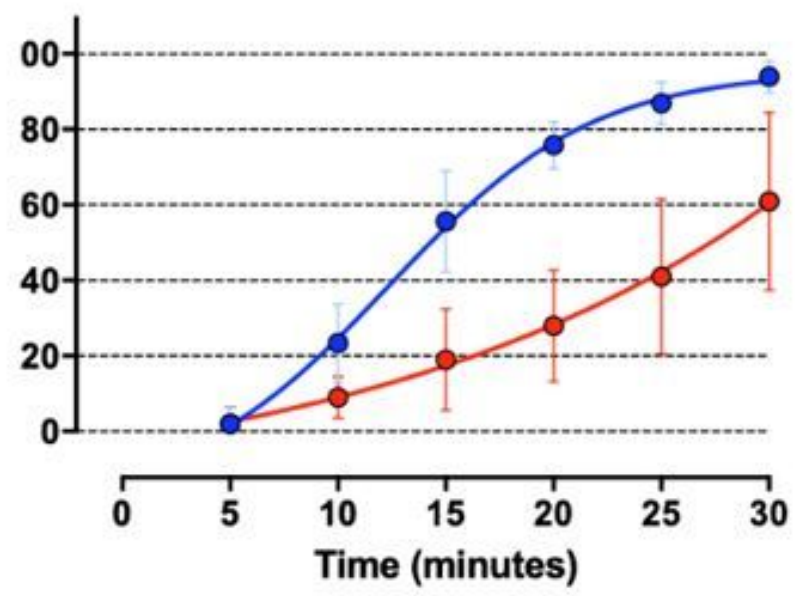

Time (minutes)

\section{Figure 1}

Simplified knockdown bioassay with Anopheles albitarsis s.s. larvae exposed to deltamethrin. 

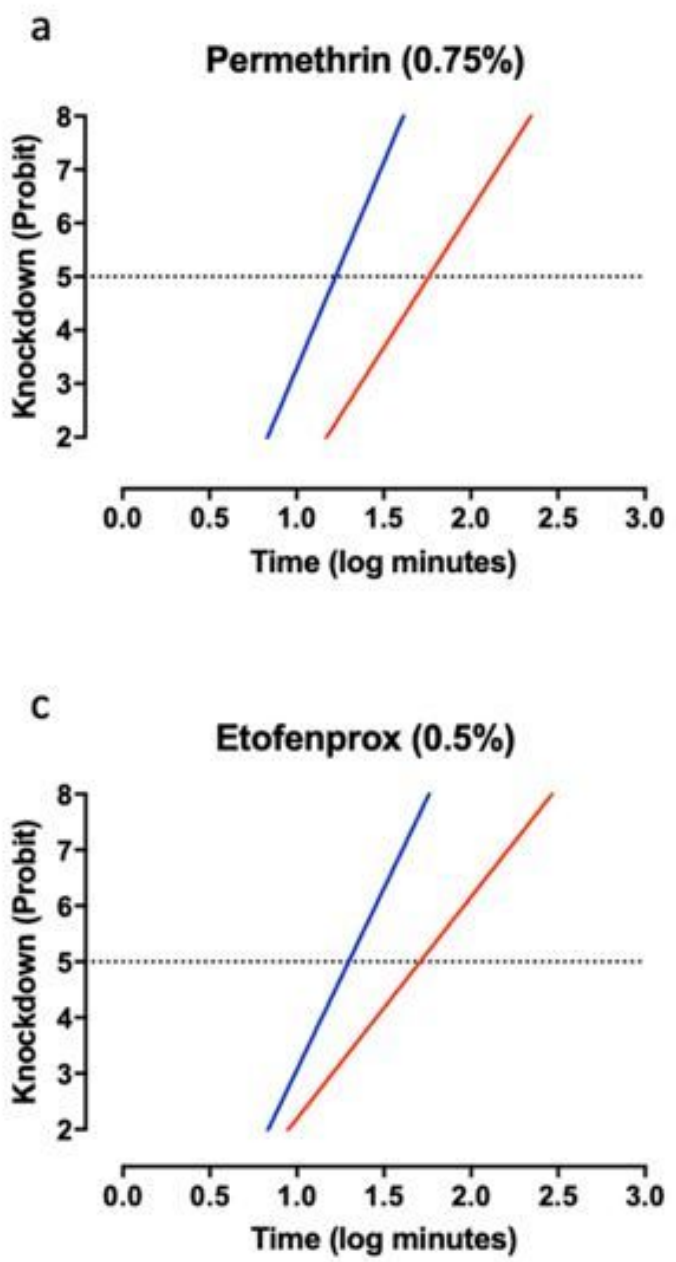

b

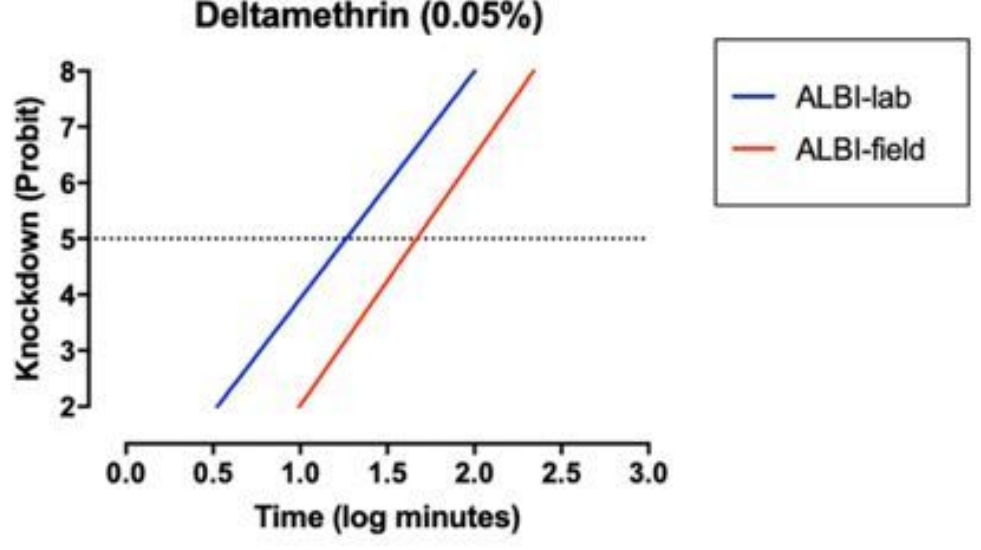

d

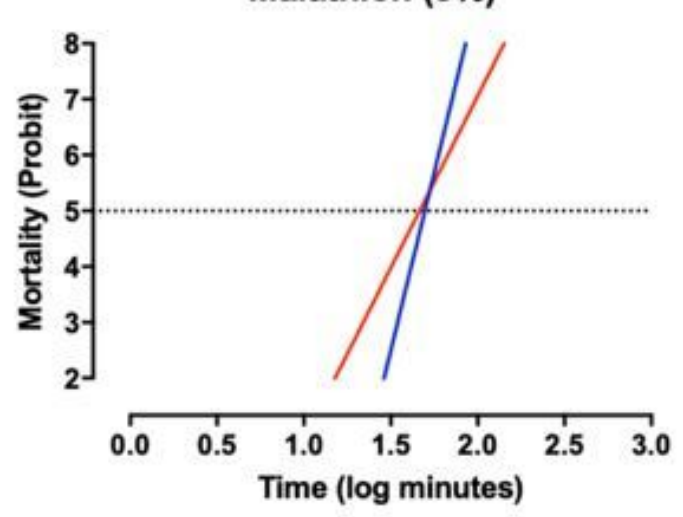

Figure 2

Susceptibility profile of Anopheles albitarsis s.s. from laboratory colony and field population from Massaranduba, SC Brazil to pyrethroids and organophosphate adulticides. 


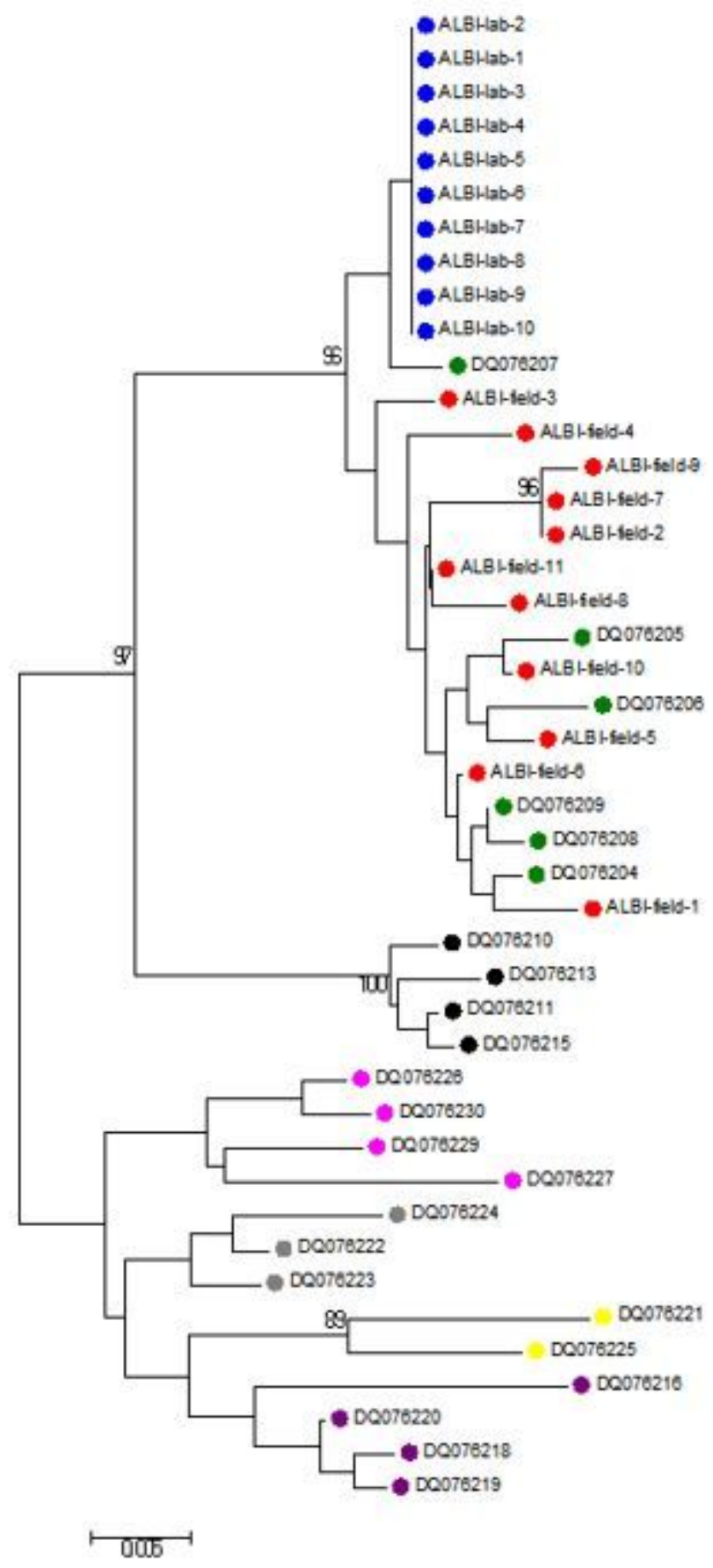

Figure 3

Neighbor-joining $(\mathrm{NJ})$ tree evidencing the phylogenetic relationship of a $\mathrm{COI}$ nucleotide fragment from Anopheles albitarsis complex species. 


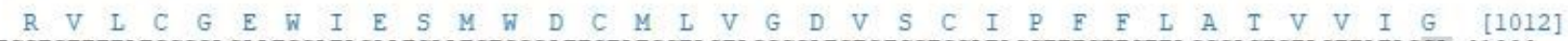

albi_1 TCGTGTTTTATGCGGAGAATGGATAGAATCAATGTGGGATTGTATGCTAGTAGGCGATGTGTCGTGCATACCTTTCTTCTTAGCGACTGTAGTTATAGGA [100]

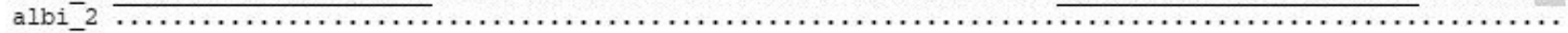

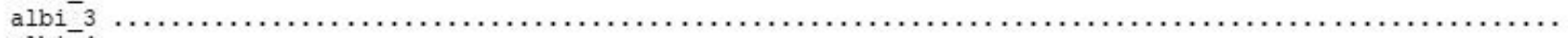

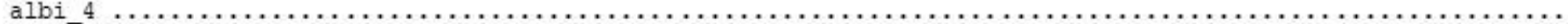

albi-5

N L/E

albi_I AACTTAGTCgtaagtgcattaactgatacaaacattgcgaacatgcgaatacttctctacataaaccttgacttttccagGTACTTAACCTGTTCTTAG [200]

albi_2

albi 3

albi-4

albi_5

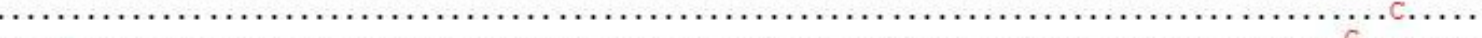

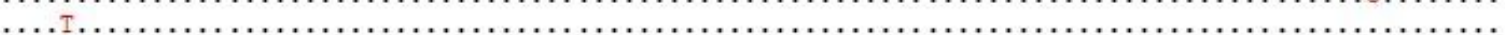

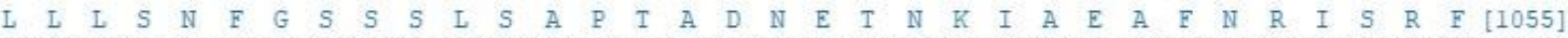

albi 1 CTTTGCTTTTGTCGAATTTTGGATCATCTTCGTTGTCAGCACCGACAGCGGATAATGAGACGAACAAAATTGCAGAGGCTTTTAACAGGATATCGCGCTT [300]

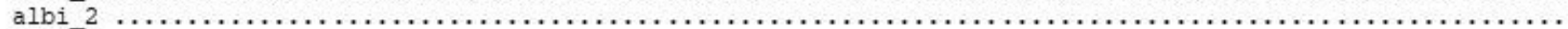

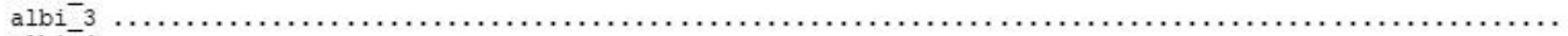

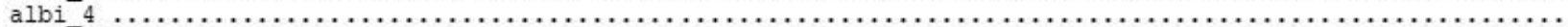

albi_5

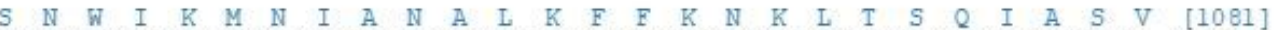

albi_1 TTCTAACTGGATAAAAATGAACATAGCGAATGCACTGAAATTCTTTAAAAACAAGTTAACAAGTCAAATTGCGTCCGTG [379]

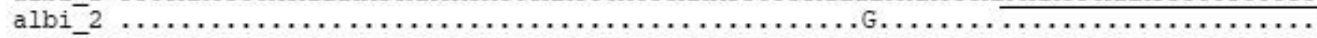

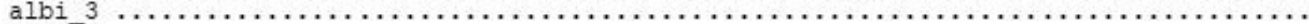

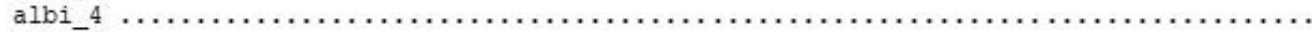

albi-5

\section{Figure 4}

Nucleotide sequence alignment and presumed amino acid translation of An. albitarsis s.s. haplotypes of a NaV gene segment 